\title{
Lateral Inhibition and Granule Cell Synchrony in the Rat Hippocampal Dentate Gyrus
}

\author{
Robert S. Sloviter ${ }^{1,2}$ and Jonathan L. Brisman' \\ ${ }^{1}$ Neurology Research Center, Helen Hayes Hospital, New York State Department of Health, West Haverstraw, New York \\ 10993 and 2 Departments of Pharmacology and Neurology, Columbia University College of Physicians and Surgeons, New \\ York, New York 10032
}

Studies of patients with temporal lobe epilepsy and of experimental models of this disorder suggest that the hippocampal dentate gyrus may be a common site of seizure onset and propagation. However, the nature of the dentate "network defect" that could give rise to spontaneous, intermittent, and synchronous population discharges is poorly understood. We have hypothesized that large expanses of the dentate granule cell layer have an underlying tendency to discharge synchronously in response to afferent excitation, but do not do so normally because vulnerable dentate hilar neurons establish lateral inhibition in the granule cell layer and thereby prevent focal discharges from spreading to surrounding segments. To address this hypothesis, we (1) identified functionally independent segments of the granule cell layer; (2) determined whether discharges in one segment evoke lateral inhibition in surrounding segments; and, (3) determined if disinhibition induces normally independent segments of the granule cell layer to discharge synchronously. Simultaneous extracellular recordings were made from two locations along the longitudinal or transverse axes of the granule cell layer using saline- and bicuculline-filled electrodes that were glued together. Leakage of $10 \mathrm{~mm}$ bicuculline from the electrode tip produced no detectable spontaneous activity. However, single perforant path stimuli evoked multiple population spikes at the bicuculline electrode and simultaneous normal responses at the nearby saline electrode. The multiple spikes evoked at the bicuculline electrode did not propagate to, and were not detected by, the adjacent saline electrode, indicating functional separation between neighboring subgroups of granule cells. Pairedpulse stimulation revealed that multiple discharges were not only restricted to one segment of the granule cell layer, but strongly inhibited surrounding segments. This lateral inhibition in surrounding segments often lasted longer than 150 msec. Finally, we evaluated granule cell activity at two normally independent sites within the granule cell layer both before and after disinhibition was induced by high frequency stimulus trains or bicuculline injection. Following a $10 \mathrm{sec}$,

\footnotetext{
Received Apr. 20, 1994; revised July 7, 1994; accepted July 15, 1994.

This research was supported by NIH Grant NS18201. We thank Drs. F. E. Dudek, D. H. Lowenstein, T. A. Pedley, and H. E. Scharfman for useful discussions and constructive criticism of the manuscript, and Dr. S. Neubort for help with figure preparation.

Correspondence should be addressed to Dr. R. S. Sloviter, Neurology Research Center, Helen Hayes Hospital, West Haverstraw, NY 10993.

Copyright (C) 1995 Society for Neuroscience $0270-6474 / 95 / 150811-10 \$ 05.00 / 0$
}

$20 \mathrm{~Hz}$ perforant path stimulus train, $2 \mathrm{~Hz}$ stimulation evoked virtually identical synchronized epileptiform discharges from normally separated sites. Similarly, intrahippocampal or intravenous bicuculline injection produced spontaneous synchronous epileptiform discharges throughout the granule cell layer. These results indicate that lateral or "surround" inhibition is an operant physiological mechanism in the normal dentate gyrus and suggest that afferent stimuli to a disinhibited dentate network evoke highly synchronized discharges from large expanses of the granule cell layer that are normally kept functionally separated by GABA-mediated inhibition.

[Key words: hippocampus, dentate gyrus, lateral inhibition, GABA, bicuculline, epilepsy]

Recent studies suggest that disinhibition of the granule cells of the hippocampal dentate gyrus may be a crucial step in the epileptogenic process that culminates in complex partial seizures of temporal lobe origin (Lothman et al., 1991; Sloviter, 1994). An understanding of how the dentate network malfunctions in temporal lobe epilepsy requires an understanding of the normal functional organization of the dentate gyrus. In 1971, Andersen and colleagues suggested that the dentate gyrus and adjoining hippocampus are organized as a series of functionally independent, parallel, transverse "slices." They proposed that activity in a given segment of the entorhinal cortex is relayed to a corresponding segment of the dentate granule cell layer, and that this activity is then conveyed sequentially through a thin slice of the CA3 and CA1 pyramidal cell layer. This "lamellar" hypothesis of hippocampal function (Andersen et al., 1971) has been questioned recently on the basis of anatomical studies that show that extensive longitudinal associational pathways exist in both the hippocampus and dentate gyrus (Amaral and Witter, 1989). Because Amaral and Witter (1989) inferred that these longitudinal associational projections constitute recurrent excitatory connections among widely separated segments of the granule cell layer, they suggested that the existence of longitudinal projections is antithetical to the concept of independent lamellar function. However, as a result of recent studies of granule cell pathophysiology associated with the loss of the dentate hilar neurons that form the longitudinal projection (Sloviter, 1987 ; 1991b), we view the possible functional significance of the dentate associational pathway differently. We have suggested that by primarily exciting inhibitory neurons in distant segments of the granule cell layer, this pathway evokes lateral inhibition, rather than excitation, and establishes functional separations in the granule cell layer as a result (Sloviter, 1994). 
The selective loss of dentate hilar cells after experimentally induced status epilepticus or head trauma (Sloviter, 1987, 1991b; Lowenstein et al., 1992) is strikingly similar to the pattern of pathology (endfolium sclerosis) found in the dentate gyrus of patients with temporal lobe epilepsy (Margerison and Corsellis, 1966; Bruton, 1988; deLanerolle et al., 1989). Because many epilepsy patients with hippocampal sclerosis have a history of prolonged febrile seizures or head trauma (Bruton, 1988; Meldrum and Bruton, 1992; Cendes et al., 1993; French et al., 1993), we have hypothesized that the loss of vulnerable hilar neurons may result in lateral disinhibition. Without lateral inhibition to establish functional separation in the granule cell layer, an enlarged expanse of the granule cell layer can be recruited to form an "epileptic aggregate" capable of responding to normal neocortical stimuli with epileptiform discharges. Thus, we have likened the dentate gyrus to the keyboard of a piano and proposed that individual lamellae are normally like individual piano keys (Sloviter, 1994). When "struck" by a focal afferent input from the entorhinal cortex, individual granule cell lamellae respond and convey that activity to a corresponding slice of the dentate hilus and CA3 pyramidal cell layer via the highly lamcllar mossy fibcr pathway (Blackstad ct al., 1970; Gaarskjaer, 1986; Amaral and Witter, 1989). When hilar neurons that form the longitudinal projection are lost following injury, lateral disinhibition results, functional separation between neighboring lamellae is lost, and lamellae coalesce functionally; that is, the "keys" become glued together. Now, the disinhibited and functionally unified segments respond to a specific afferent input with a nonspecific, epileptiform discharge from an enlarged excitable aggregate of granule cells (Sloviter, 1994).

This article addresses the three cornerstones of this hypothesis. The first is that adjacent segments of the normal granule cell layer are functionally independent, and excitation evoked in one segment does not propagate to surrounding segments. This view is supported by the results of a study by Steward and colleagues (1990), which showed that multiple granule cell population spikes evoked in the immediate region of a bicucullinefilled recording electrode did not affect the potential evoked simultaneously at an adjacent saline-filled recording electrode that was estimated to lie only $0.5-1.0 \mathrm{~mm}$ in the longitudinal direction. The second cornerstone is that excitation in one segment of the granule cell layer is not only restricted to that segment, but actively inhibits granule cell excitability in adjacent segments, that is, evokes lateral inhibition. The third issue is that the granule cells in each functionally independent segment of the granule cell layer have an inherent tendency to join together with surrounding lamellae to discharge synchronously when excited, but that they are normally prevented from doing so by lateral inhibition.

Experiments were designed to answer the three questions central to this hypothesis. First, what are the spatial and axial characteristics of functional separation in the granule cell layer? Second, does lateral inhibition occur in the granule cell layer? Third, when inhibition is reduced, do normally independent segments of the granule cell layer coalesce functionally and begin to discharge synchronously and repetitively?

\section{Materials and Methods}

Animal treatment

Male Sprague-Dawley descendant rats weighing 250-350 gm were treated in accordance with the guidelines set by the New York State Department of Health and the National Institutes of Health for the humane treatment of animals. Rats were anesthetized with urethane $(1.25 \mathrm{gm} /$ $\mathrm{kg}$, i.p.; $250 \mathrm{mg} / \mathrm{ml}$ saline). A femoral vein cannula was implanted in some cases to permit intravenous injection of bicuculline base (Sigma Chemical, St. Louis, MO; $1 \mathrm{mg} / \mathrm{ml} 1 \%$ citric acid in saline). Rats were placed in a Kopf sterentaxic device and the top of the skull was made level. A bipolar stainless steel stimulating electrode (NE-200; Rhodes Medical) was placed in the angular bundle of the perforant path (4.5 $\mathrm{mm}$ lateral from the midline suture and immediately rostral to the lambdoid suture). Each pair of recording electrodes was lowered into the brain (approximately $2 \mathrm{~mm}$ lateral from the midline suture, $3 \mathrm{~mm}$ rostral to the lambda, and $3.5 \mathrm{~mm}$ below the brain surface) and placed in the dorsal (suprapyramidal) blade of the granule cell layer by optimizing the characteristic shape of the evoked potential. Responses were recorded in both the longitudinal and transverse axes by placing the tips approximately parallel or perpendicular to the longitudinal axis of the hippocampus (approximately $30^{\circ}$ from the sagittal plane). Biphasic current pulses ( $0.1 \mathrm{msec}$ duration) were generated by a Grass S88 stimulator with a Grass stimulus isolation unit. Potentials were amplified by two Grass preamplifiers, displayed simultaneously on a Nicolet series 420 digital oscilloscope, and stored on diskette.

\section{Stimulation and recording}

Given the anatomical features of the perforant path, it is possible to stimulate the angular bundle of perforant path fibers and activate the entire dorsal dentate gyrus simultaneously (Andersen et al., 1966). By doing so, a single stimulus produces similar events simultaneously throughout the longitudinal extent of the dorsal dentate gyrus. Using the bicuculline electrode method devised by Steward et al. (1990), we were able to increase the postsynaptic excitability of a small population of granule cells located around the tip of one electrode, and then determine the effect of that enhanced discharge on responses to the same afferent stimuli recorded simultaneously at a nearby site within the granule cell layer.

Paired electrodes type 1 . To identify functionally distinct segments of the granule cell layer, we modified the method of Steward et al. (1990) by gluing two glass microelectrodes together in order to verify microscopically the distance between the electrode tips. Glass electrodes ( 1.5 mm outer diameter; World Precision Instruments, Sarasota, FI) were pulled on a Kopf electrode puller and glued together with cyanoacrylate glue to produce electrodes of matched length and verified tip separations (50-1500 microns). Tip separations were measured under a microscope on a micrometer slide. Accurate measurements could be made microscopically within $\approx 15 \mu$. Tip separation was measured as the distance between the inside edges of the two electrode tips. One electrode of each pair was filled with $0.9 \% \mathrm{NaCl}$ and the other with $10 \mathrm{~mm}$ bicuculline methiodide (BMI; Sigma) dissolved in $0.9 \% \mathrm{NaCl}$. Tip resistance was typically $<1 \mathrm{M} \Omega$.

Paired electrodes type 2. To determine if increased excitation in one segment of the granule cell layer produced lateral inhibition in adjacent segments, we needed to evaluate granule cell population responses to perforant path stimulation both before and after injection of bicuculline from one electrode. This was not possible with the type 1 electrode, from which bicuculline apparently diffuses continuously. To evaluate inhibition both before and after BMI injection, we used a $1 \mu \mathrm{l}$ Hamilton syringe (\#7001) as both a recording electrode and an injector. A gold male pin connector was soldered to the shaft of the syringe needle, which was then insulated with a thin coating of Epoxylite. The tip of the needle was left uncoated to permit it to act as a recording electrode. A salinefilled glass microelectrode was then glued to the shaft of the Hamilton syringe and the tip separation $(800 \mu)$ was measured. BMI $(10 \mathrm{~mm})$ was pulled into the syringe, followed by a small volume of boiling agar ( 2 $\mathrm{gm}$ agar $/ 60 \mathrm{ml}$ water) to form a plug to prevent leakage of BMI. After simultaneous recording of control granule cell responses to perforant path stimulation from both electrodes, BMI was injected through the syringe/electrode using a Kopf model 5000 microinjector.

Paired electrodes type 3 . Two saline-filled electrodes with a tip separation of 1.0 or $1.5 \mathrm{~mm}$ were used to determine the degree of granule cell synchrony at two normally separated sites after a train of perforant path stimuli that overcame inhibition or after intravenous or intrahippocampal injection of bicuculline.

\section{Results}

Functional separation in the normal dentate gyrus

When first lowered into the granule cell layer, both recording electrodes recorded virtually identical, normal granule cell field 

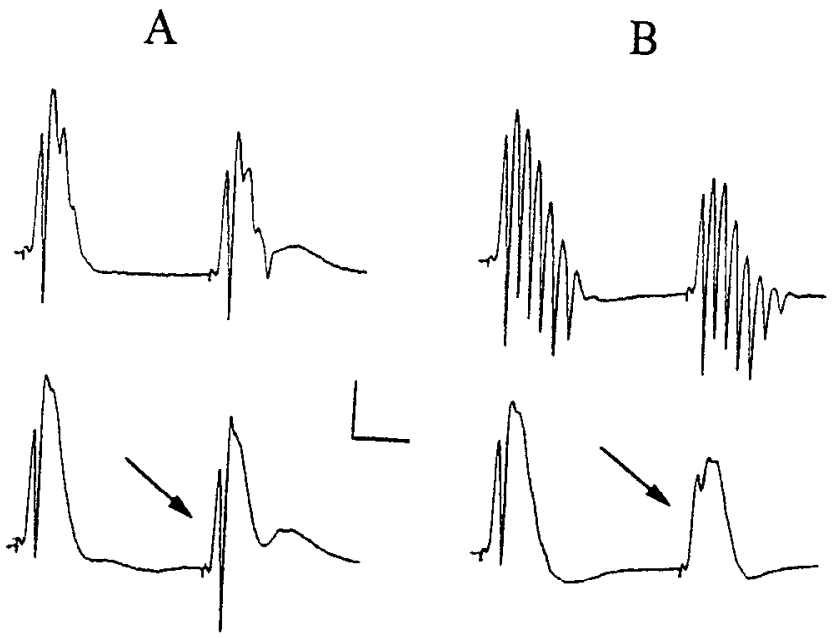

Figure 1. Functional separation and lateral inhibition in the granule cell layer of the normal rat dentate gyrus. Simultaneous dentate granule cell responses to $0.3 \mathrm{~Hz}$ perforant path stimuli were recorded by paired glass electrodes, one containing $10 \mathrm{~mm}$ bicuculline methiodide, the other containing saline. Evoked potentials were recorded along the longitudinal axis by electrodes with a verified tip separation of $670 \mu . A$, Within seconds after electrode insertion, the bicuculline electrode (top trace) records a slightly disinhibited response, and the saline electrode (bottom trace) records a normal response. Note that at this low stimulus frequency, paired-pulse stimulation at a $40 \mathrm{msec}$ interpulse interval produces no suppression of the second spike (arrow). $B$, Less than 1 min later, the bicuculline electrode records multiple granule cell responses. As granule cell discharges develop at the bicuculline site, paired-pulse inhibition increases dramatically at the adjacent saline electrode (arrow). Thus, discharges evoked in one segment of the granule cell layer are not only restricted to that segment, but produce lateral inhibition in surrounding segments. Calibration bar: $5 \mathrm{mV}$ and $10 \mathrm{msec}$.

potentials in response to $0.1 \mathrm{~Hz}$ perforant path stimuli. Within seconds after placement within the granule cell layer, the bicuculline electrode began to record multiple granule cell population spikes (Fig. $1 A$, top trace) that were not detected by the adjacent saline electrode in response to single or paired stimuli (Fig. 1 $A$, bottom trace). Within 1-2 min of lowering the electrodes into the granule cell layer, the number of population spikes evoked at the bicuculline electrode increased and reached a maximum number of discharges (unique for each electrode) that was stable for more than an hour (Fig. $1 B$, top trace). In contrast; when spontaneous activity was recorded, no discharges were detected at either electrode, despite presumably continuous leakage of bicuculline from one electrode.

The aforementioned sequence of events that occurred after placement of paired electrodes in the granule cell layer was highly reproducible within the same animal when the electrodes were raised above the hippocampus and then reinserted after a period of time (5-15 min) sufficient for bicuculline to be cleared from the tissue. Each experiment was routinely repeated at least twice in each animal. The effects of bicuculline leakage from one electrode were also highly rcproducible qualitatively bctween animals $(n>25)$.

Normal and abnormal responses (as shown in Fig. $1 B$ ) were recorded simultaneously from paired electrodes with verified tip separations as small as $200 \mu$. With tip separations of 50 or $100 \mu$, both electrodes recorded similar bicuculline-enhanced potentials simultaneously, presumably because bicuculline diffused rapidly to the saline electrode tip and/or both electrodes recorded from overlapping granule cell subpopulations. Thus,

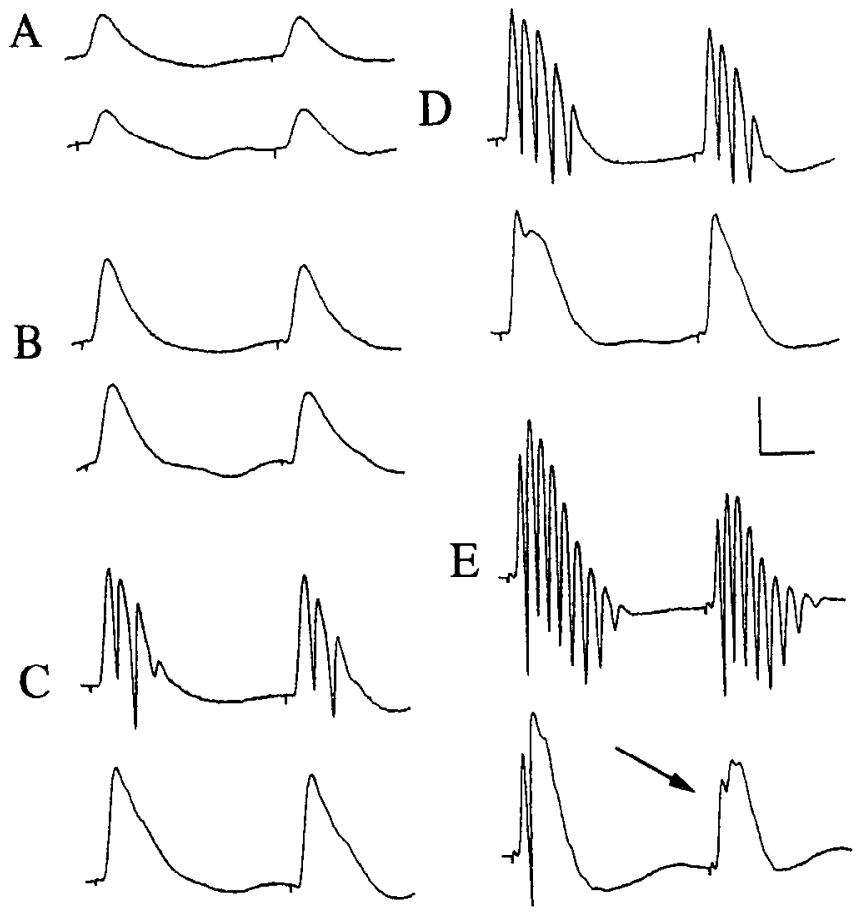

Figure 2. Effect of bicuculline on responses in independent segments of the granule cell layer to increasing afferent stimulus voltage. The top and bottom traces of each pair of traces were recorded from the bicuculline and saline electrodes, respectively, after bicuculline leakage had stabilized as shown in Figure $1 B . A$ and $B$, Similar dendritic field "EPSPs" in response to low stimulus voltage $(A, 3 \mathrm{~V} ; B, 3.5 \mathrm{~V})$. $C$ and $D$, As voltage increases, the afferent stimulus evokes multiple population spikes superimposed on the positive dendritic field depolarization at the bicuculline electrode, but primarily dendritic field depolarizations at the saline electrode $(C, 5 \mathrm{~V} ; D, 6 \mathrm{~V}) . E$, With supramaximal stimulus voltage $(30 \mathrm{~V})$, one stimulus pair simultaneously evokes multiple spikes at the bicuculline electrode and single population spikes with second spike suppression at the saline electrode (arrow). These responses show that, despite bicuculline diffusion from the tip of one electrode, a single pair of afferent stimuli produce similar dendritic excitation in functionally distinct segments of the granule cell layer. Bicuculline specifically decreases the somal spike threshold such that similar dendritic excitation produces multiple population spikes at the bicuculline electrode that do not propagate longitudinally. All stimuli are paired pulses $40 \mathrm{msec}$ apart delivered at $0.1 \mathrm{~Hz}$. Calibration, $5 \mathrm{mV}$ and $10 \mathrm{msec}$.

although this method did not permit an accurate determination of the minimum distance between functionally independent segments of the granule cell layer, functional separation was clearly evident in granule cell subpopulations as close as $200 \mu$. Assuming that bicuculline diffuses some distance toward the saline electrode, functional separation presumably exists at distances considerably less than $200 \mu$. These results with paired electrodes demonstrate that the field potentials evoked by afferent stimulation are generated by very small spheres of granule cells around the electrode tips and that even large amplitude, multiple discharges neither propagate to, nor are detected by, a second electrode located only a few hundred microns away.

\section{Lateral inhibition in the granule cell layer}

Comparison of responses to paired-pulse stimulation both before and after multiple discharges developed at the bicuculline electrode revealed that multiple discharges evoked in one segment of the granule cell layer were not only restricted to that segment, but were associated with a dramatic increase in pairedpulse inhibition in surrounding segments (Fig. 1). Significantly, 

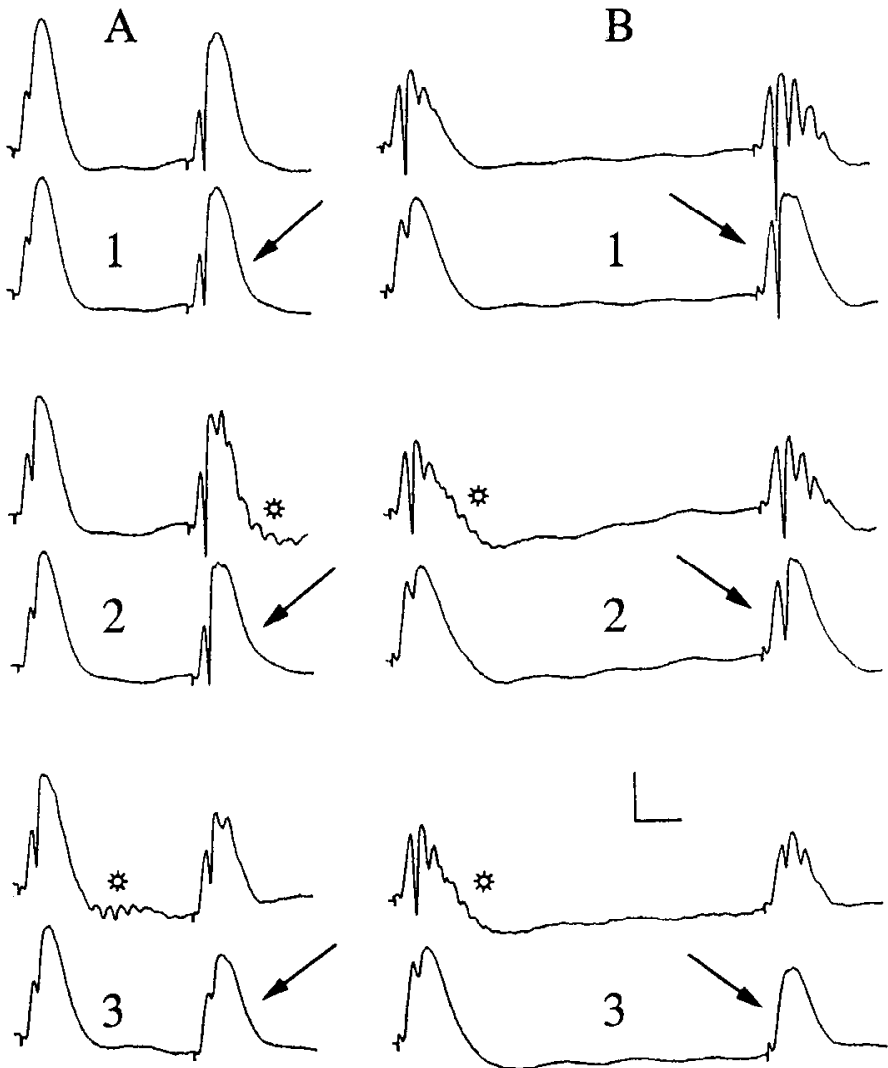

Figure 3. Lateral inhibition in the dentate gyrus. Granule cell responses to perforant path stimuli were recorded simultaneously by longitudinally oriented bicuculline- and saline-filled electrodes that had tip separations of $380 \mu(A)$ and $1000 \mu(B) . A$, Upon initial insertion, both the BMI (top trace of each pair) and saline (bottom trace) electrodes record "normal" evoked responses to $0.3 \mathrm{~Hz}$ paired-pulse stimuli delivered at a 40 msec interpulse interval $(A, l)$. Seconds later, bicuculline diffusion from the tip produces low-amplitude multiple discharges on the second waveform $(A, 2$; asterisk) but no inhibition of the second waveform's population spike recorded simultaneously at the saline electrode (arrow). When the next stimulus pair evokes similar multiple discharges on the first waveform at the BMI electrode $(A, 3$; asterisk), spike suppression in the second waveform at the saline electrode is evident (arrow). Note that the discharge in $A, 3$ evokes lateral inhibition (spike suppression at the saline electrode; arrow) and recurrent inhibition of the second spike at the BMI electrode. $B$, Three consecutive traces of responses in a different rat to $0.1 \mathrm{~Hz}$ paired stimuli delivered $80 \mathrm{msec}$ apart. $B, 1$, Note that recordings made soon after electrode insertion show early BMI effects (multiple spikes) primarily on the second waveform. $B, 2$, As lowamplitude discharges are produced on the first waveform (asterisk), spike suppression occurs at the saline electrode (arrow). B,3, With the next stimulus, discharges at the first waveform at the BMI electrode fully suppress the spike at the saline electrode (arrow), as well as increase inhibition at the BMI electrode (second spike in top trace in $B, 3$ ). Note the efficacy and selectivity of the effect of BMI, that is, complete suppression of the second spike without any apparent effect on the first potential. These recordings show that lateral inhibition does not require full disinhibition in the segment in which discharges originate. Calibration, $5 \mathrm{mV}$ and $10 \mathrm{msec}$.

the traces shown in Figure 1 indicate that the lateral inhibition produced by bicuculline was highly selective in that only the second population spike of each pair was inhibited (Fig. $1 B$, bottom trace). If bicuculline were affecting granule cell excitability in other segments nonspecifically, the first of two spikes would also be affected.

The cellular mechanism by which the $\mathrm{GABA}_{\mathrm{A}}$ receptor an- tagonist bicuculline induced granule cell discharges is illustrated by the simultaneous responses of two distinct segments to increasing stimulus voltage. Figure 2 shows that at low stimulus voltage, the evoked dendritic field "EPSPs" (Andersen et al., 1966) were of similar amplitude (Fig. $2 A, B$ ). Thus, each perforant path stimulus produccd similar amplitude dendritic field depolarizations in independent segments of the granule cell layer despite the presence of bicuculline at one site. With increasing voltage, the same degree of dendritic excitation produced very different somal responses recorded simultaneously in independent segments. The responses recorded at the saline electrode exhibited "normal" responsiveness, that is, a relatively high population spike threshold for a given dendritic depolarization. At the bicuculline electrode, however, the same dendritic excitation produced multiple spikes (Fig. 2C,D). With a further increase in stimulus voltage, additional multiple population spikes were evoked at the bicuculline site, whereas strongly inhibited potentials with single population spikes were recorded at the nearby saline electrode (Fig. $2 E$ ). Thus, bicuculline produced a decreased spike threshold for a given degree of dendritic depolarization.

Granule cell discharges evoked at the bicuculline electrodc were reliably associated with lateral inhibition at the saline electrode, as shown in Figure $2 B$, which is $>90 \%$ suppression of second spike amplitude, in all cases tested ( $n=23$ rats), and with all tip separations used to evaluate lateral inhibition $(380$, $480,600,650,670,700,710,750,780,800,840,900,1000$, 1100 , and $1500 \mu$ ). Lateral inhibition was recorded in both the longitudinal and transverse axes. All figure illustrations are of recordings made along the longitudinal axis.

\section{The nature of lateral inhibition}

Although Figures 1 and 2 show lateral inhibition increasing in one segment of the granule cell layer as large amplitude, multiple discharges develop in another segment, lateral inhibition does not require large amplitude population spikes in the instigating segment. Immediately after paired electrodes were lowered into the granule cell layer, normal responses were recorded at both sites (Fig. 3AI). In the first seconds of recording and presumably before sufficient bicuculline diffused from the tip to produce the large amplitude granule cell discharges shown in Figures 1 and 2, small amplitude discharges ("ripples") were often observed at the bicuculline electrode (Fig. $3 A 2$ ). The relationship between the first of two potentials recorded by the bicuculline electrode and the second of two potentials recorded $40-80 \mathrm{msec}$ later by the saline electrode was apparent from unanticipated variations in the responses to consecutive, identical stimulus pairs. When a pair of stimuli evoked ripples in only the second of two waveforms at the bicuculline electrode, no spike suppression was evident on the second waveform recorded at the saline electrode (Fig. 3A2). Conversely, when an identical pair of afferent stimuli evoked a ripple discharge in only the first waveform recorded at the bicuculline electrode, strong spike suppression was evident in the second waveform recorded at the saline electrode (Fig. 3A3). In addition to the observed increase in paired-pulse suppression at the saline electrode, that is, inhibition across segments, ripple discharges also increased paired-pulse suppression at the bicuculline electrode, that is, inhibition within the segment (Fig. 3A3,B3).

These results suggest that as it begins to diffuse, bicuculline disinhibits a very small sphere of granulc cclls around the electrode tip. Multiple discharges of these cells (ripples), as shown 
A
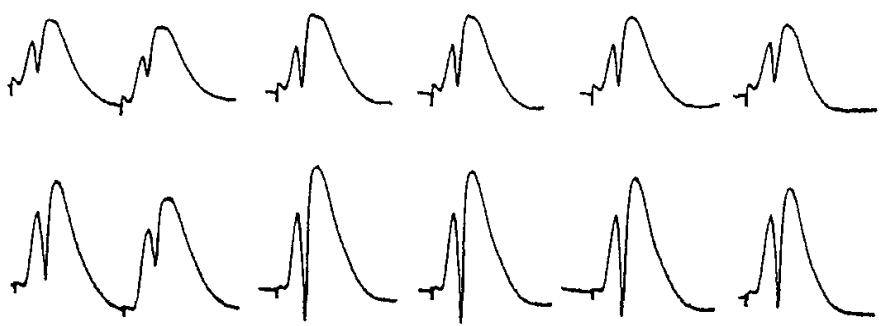

B
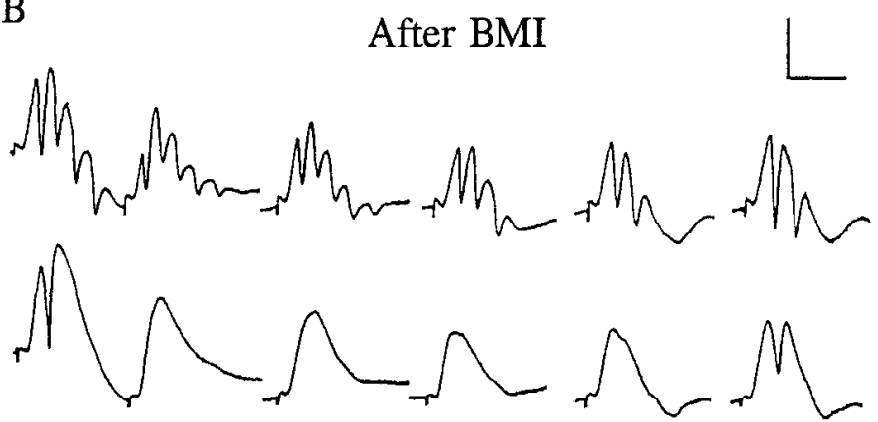

$20 \mathrm{~ms}$

80

120

160
Figure 4. Paired-pulse inhibition in response to $0.2 \mathrm{~Hz}$ perforant path stimulation before and after bicuculline injection. $A$, Evoked responses before BMI injection from electrodes oriented along the longitudinal axis. The first pair of potentials are the responses to stimuli delivered $20 \mathrm{msec}$ apart. Subsequent potentials are the second response to paired stimuli of increasing interpulse interval $(40,80,120$, and $160 \mathrm{msec})$. The top trace of each pair is the recording made with the BMI syringe/ electrode. The bottom trace is the response at the saline-filled glass electrode glued to the insulated barrel of the Hamilton syringe/electrode. Note that before BMI injection $(A)$, the paired-pulse suppression at 0.2 $\mathrm{Hz}$ stimulation is partial at $20 \mathrm{msec}$ and nil at longer interpulse intervals. $B$. Seconds after injection of $0.05 \mu 110 \mathrm{mM}$ BMI from the BMI syringe/ electrode, multiple spikes are recorded at the BMI site and strong, longlasting lateral inhibition is recorded at the saline electrode located 800 $\mu$ longitudinally. Note long-lasting ( $>160 \mathrm{msec}$ ) lateral inhibition and the decrease in the amplitude of the dendritic field "EPSP," which appears to be maximal at an interpulse interval of $80 \mathrm{msec}$. No paroxysmal discharges or voltage changes of any kind were detected during the interval between the first discharge at the BMI electrode and the test pulses at both electrodes. Thus, the long-lasting spike suppression at the saline electrode is apparently due to the initial discharge at the BMI electrode. Calibration, $5 \mathrm{mV}$ and $10 \mathrm{msec}$.

in Figure $3, A$ and $B$, produce lateral inhibition at the adjacent saline electrode, but also increase inhibition in the larger sphere of granule cells from which the bicuculline electrode records but which has not yet been exposed to a significant concentration of bicuculline. As bicuculline continues to diffuse, the entire sphere of cells from which the bicuculline electrode records begins to discharge synchronously, producing the large amplitude discharges shown in Figure $1 B$.

Although the use of the paired glass electrodes clearly demonstrated lateral inhibition, there was insufficient time after lowering the electrodes, and before bicuculline diffused from the tip, to optimize the stimulating electrode placement and determine spike amplitudes at different interpulse intervals. Therefore, the Hamilton syringe/electrode (type 2, see Materials and Methods), was designed and constructed to permit evaluation
A
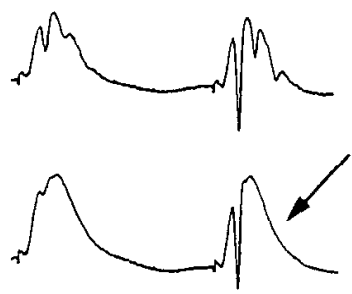

B
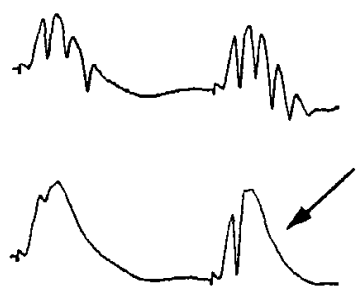

C
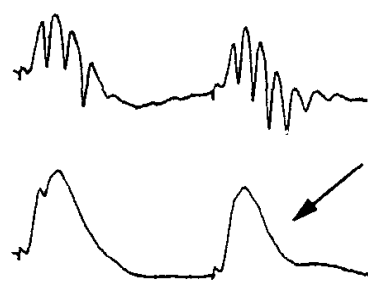

$\mathrm{D}$
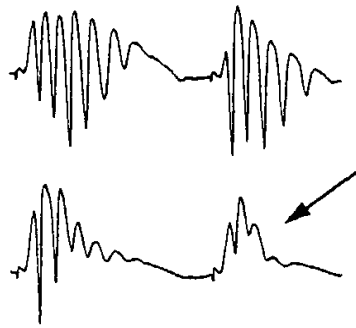

$\mathrm{E}$
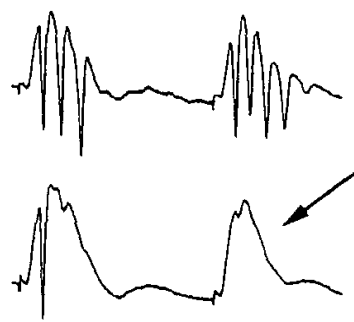

$\mathrm{F}$
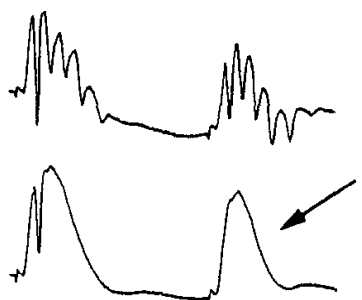

Figure 5. Bicuculline blockade of bicuculline-induccd lateral inhibition. $A-F$, Sequence of responses from BMI and saline electrodes after injection of bicuculline $(0.5 \mu \mathrm{l} 10 \mathrm{mM} \mathrm{BMI})$ from the syringe/electrode. $A-C$, Immediately after injection, multiple spikes increased at the BMI syringe/electrode and produced complete spike suppression (arrows) at the saline electrode located $800 \mu$ away. $D$, As bicuculline spread to the saline electrode, lateral inhibition was blocked and multiple spikes were recorded from both electrodes. $E$ and $F$, As bicuculline cleared from the tissue, lateral inhibition was restored at the saline electrode (arrows). This sequence indicates that lateral inhibition is GABA mediated. Electrodes were oriented along the longitudinal axis. Calibration, $5 \mathrm{mV}$ and $10 \mathrm{mses}$.

of granule cell inhibition and excitability both before and after bicuculline was injected. Before bicuculline injection, both electrodes recorded similar and stable normal potentials in response to perforant path stimulation (Fig. $4 A$ ). The degree of pairedpulse inhibition evoked by $0.1-0.3 \mathrm{~Hz}$ stimulation was evaluated at different interpulse intervals. At these low stimulus frequencies, paired-pulse suppression is partial at a $20 \mathrm{msec}$ interpulse interval and absent at longer intervals (Fig. $4 A$ ), as described in detail previously (Sloviter, 1991a).

Within seconds after bicuculline injection $(0.05 \mu 10 \mathrm{~mm}$ BMI), multiple population spikes developed at the bicuculline syringe/electrode (Fig. 4B, upper traces). As this occurred, the second of two potentials evoked at the saline electrode by the 
same perforant path stimuli was completely suppressed, and the amplitude of the dendritic field "EPSP" was decreased (Fig. 4B, lower traces). Inhibition of the second population spike occurred despite a relatively unaffected first population spike. The magnitude of lateral inhibition produced by bicuculline was extraordinary in that complete suppression of large amplitude population spikes was consistently produced $(n=14)$, even at the low stimulus frequencies used, and often lasted more than 150 msec (Fig. $4 B$ ). It should be noted that injection of this small volume of BMI was imprecise. The agar plug constituted part of the injection volume and we suspect that little BMI was released from the syringe. Rather, disturbance of the plug probably allowed BMI to diffuse out passively in minute concentration, much like the glass electrode.

The GABA-mediated nature of bicuculline-induced latcral inhibition was apparent from experiments in which larger volumes of bicuculline $(0.5 \mu 110 \mathrm{~mm}$ BMI) were injected. Shortly after injection, multiple granule cell population spikes were produced at the bicuculline electrode and complete spike suppression was produced at the saline electrode (Fig. 5A-C). However, as the bicuculline presumably spread, lateral inhibition decreased at the saline electrode (Fig. 5D). As bicuculline then cleared from the tissue, lateral inhibition was restored at the saline electrode (Fig. $5 E, F$ ).

Lateral inhibition was produced in the septal portion of the dorsal dentate gyrus by bicuculline release in more temporal segments of the dorsal granule cell layer, and in the temporal portion of the dorsal dentate gyrus by more septal injections. Therefore, these results demonstrate that focal discharges induced in, and restricted to, any single segment of the granule cell layer produce strong and long-lasting inhibition, that is, transverse or longitudinal lateral inhibition, in surrounding segments of the granule cell layer, both close to and distant from the site of the focal discharges.

\section{Disinhibition-induced granule cell synchrony in the dentate gyrus}

Finally, experiments were designed to determine if normally independent segments of the granule cell layer have a tendency to discharge together synchronously when inhibition is overcome reversibly by a stimulus train (Andersen and Lømo, 1967; Ben-Ari et al., 1979; Sloviter, 1983; Thompson and Gahwiler, 1989 ) or by systemic or intrahippocampal bicuculline (Sloviter, 1991a).

Two saline-filled electrodes with a tip separation of $1 \mathrm{~mm}$ recorded independent responses to perforant path stimulus trains delivered at $20 \mathrm{~Hz}$ for $10 \mathrm{sec}$. In the first seconds of the train, $20 \mathrm{~Hz}$ stimulation evoked large amplitude population spikes with recurrent inhibition, that is, alternating population spikes and field "EPSPs" (Fig. 6B). Toward the end of the $10 \mathrm{sec}$ train, stimulation overcame inhibition; that is, each $20 \mathrm{~Hz}$ stimulus evoked a large amplitude population spike (Fig. 6C). Immediately after cessation of the stimulus train, and before inhibition recovered, $2 \mathrm{~Hz}$ stimulation evoked nearly identical synchronized epileptiform discharges at both saline electrodes (Fig. 6E). That each electrode was recording the synchronous discharges of normally independent and nonoverlapping granule cell subpopulations was evident from recordings in which large amplitude population spikes were occasionally present at one recording site but absent at the other (Fig. $6 E$, arrows). The same indication is evident from recordings that showed that immediately before the $2 \mathrm{~Hz}$ posttrain stimuli evoked synchronous repetitive discharges at both sites, one electrode recorded population spikes and the other electrode recorded field depolarizations that would soon become population spikes (Fig. 6D). Identical results were produced with saline electrodes with a tip separation of $1.5 \mathrm{~mm}(n=6$ at $1 \mathrm{~mm}$ and $n=3$ at $1.5 \mathrm{~mm})$.

Although the posttrain epileptiform discharges recorded at both saline electrodes were highly synchronous, it was possible that the synchrony within independent segments was due not to an inherent tendency of granule cells to discharge synchronously, but rather, because both discharges were triggered initially by the same perforant path stimuli. To address this possibility, we recorded spontaneous granule cell activity in two functionally independent segments after intrahippocampal or intravenous injection of bicuculline $(0.5 \mu \mathrm{l}$ of $25 \mathrm{~mm}$ BMI through the Hamilton syringe/electrode or $0.75 \mathrm{mg}$ bicuculline base $/ \mathrm{kg}$ i.v.). Within seconds after bicuculline injection by either route, highly synchronous yet clearly distinct spontaneous granule cell epileptiform discharges were recorded simultaneously from both recording electrodes (Fig. 7). Spontaneous granule cell discharges continued for approximately 2 or 20 min after intravenous $(n=6)$ or intrahippocampal $(n=4)$ injection, respectively.

These results demonstrate that when granule cell inhibition is overcome reversibly by afferent stimulation or by bicuculline, normally independent segments of the granule cell layer join together to discharge spontaneously in a highly synchronous manner.

\section{Discussion}

These results demonstrate for the first time that (1) focal discharges induced in one segment of the dentate granule cell layer are restricted to that segment by GABA-mediated inhibition in both the longitudinal and transverse directions; (2) discharges in one segment of the granule cell layer produce highly effective lateral or "surround" inhibition in neighboring segments; and, (3) when inhibition is reduced, normally independent segments of the granule cell layer coalesce functionally to generate spontaneous and synchronous repetitive discharges.

\section{Relevance to the normal functional organization of the dentate gyrus}

The results of these experiments clarify several aspects of the functional organization of the normal dentate gyrus. The dentate gyrus is a laminar and relatively simple structure in that it consists of a tightly packed population of principal cells (granule cells) and a variety of nonprincipal cells that are presumed to regulate the excitability of the granule cells (Andersen et al., 1966). The perforant path, which is the main excitatory afferent projection from the neocortex to the dentate gyrus (Ramón y Cajal, 1893, 1968; Lorente de Nó, 1934), innervates and excites dendrites of granule cells and nongranule cells alike (Scharfman, 1991). Once driven to discharge by afferent stimuli, the granule cells excite a thin transverse slice of the CA3 pyramidal cell layer via the highly lamellar mossy fiber pathway (Blackstad et al., 1970; Gaarskjacr, 1986; Amaral and Witter, 1989).

Although lateral inhibition has not been previously described in the normal hippocampal formation, its existence should not be surprising because lateral inhibition is an established mechanism in other brain regions. For example, in the cerebellum, the parallel fibers of the granule cells excite a limited number of Purkinje cells as well as inhibitory neurons that inhibit the Purkinje cells adjacent to the largeted Purkinje cells (Eccles, 1973). In the olfactory bulb, afferent stimuli to mitral cells also 
A
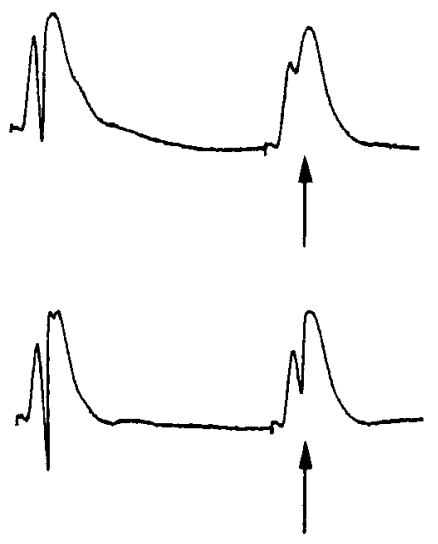

B
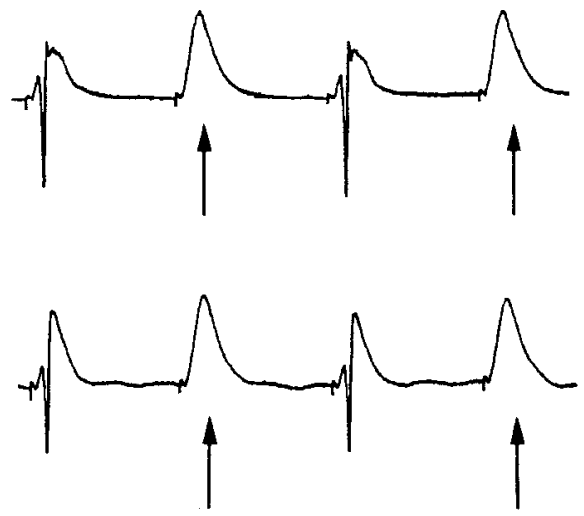

$\mathrm{C}$
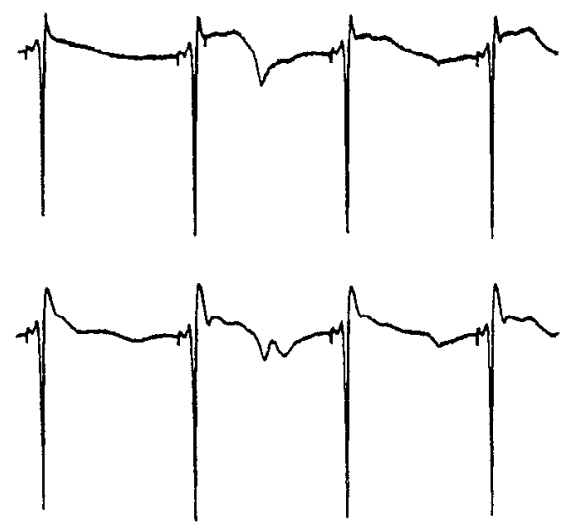

$\mathrm{D}$

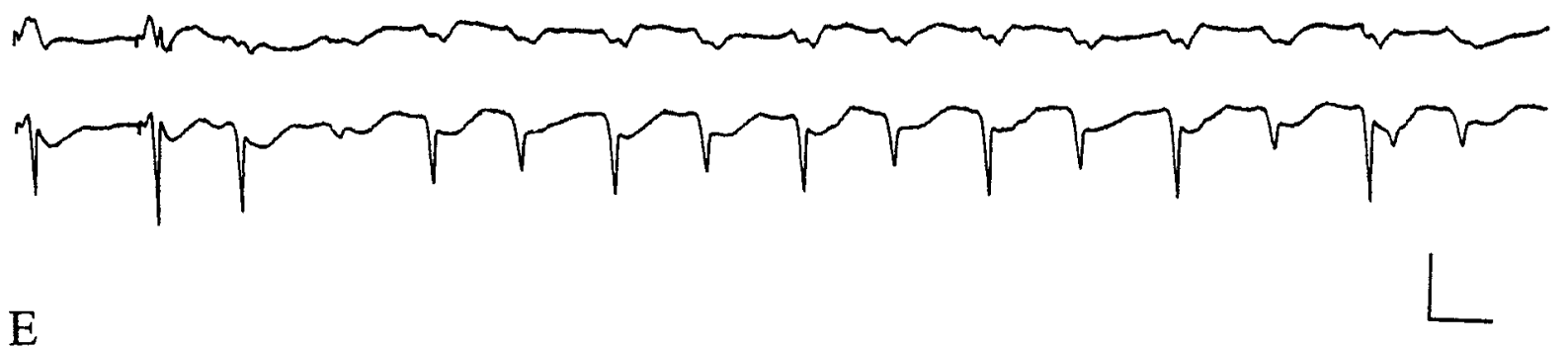

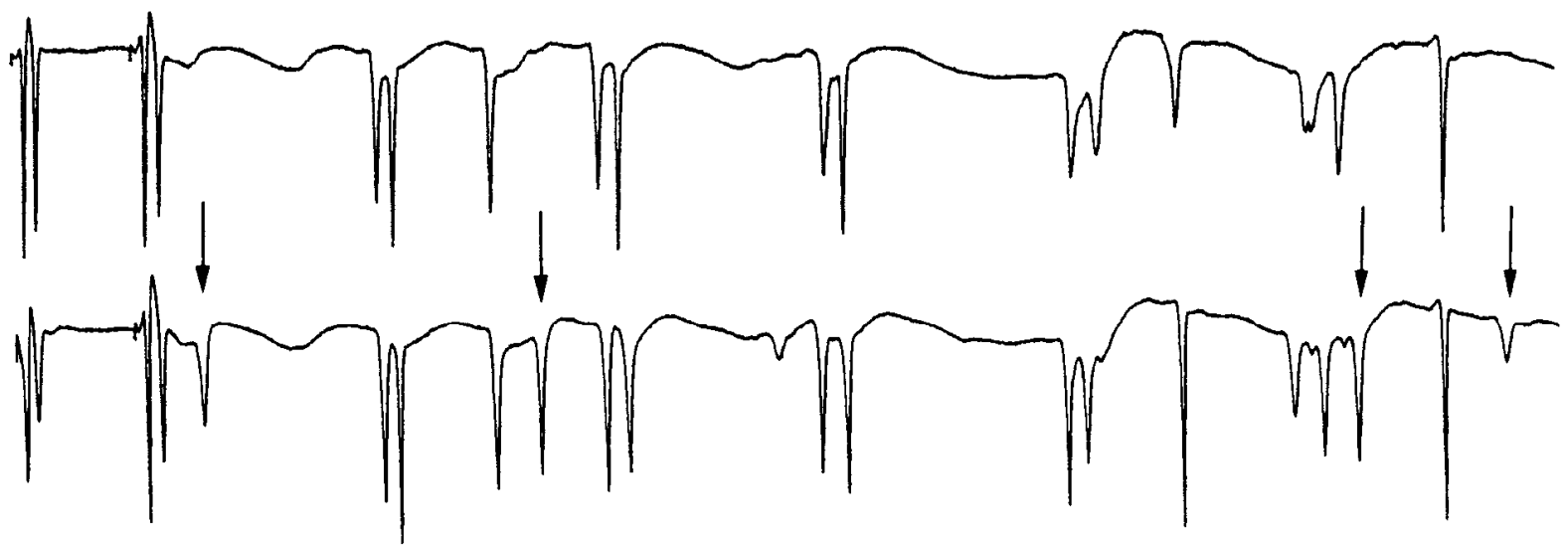

Figure 6. Granule cell synchrony after stimulus train-induced disinhibition. Responses to $2 \mathrm{~Hz}$ paired-pulse perforant path stimulation were recorded from two saline electrodes placed $1.0 \mathrm{~mm}$ apart along the longitudinal axis of the granule cell layer before and after a $10 \mathrm{sec}$ to $20 \mathrm{~Hz}$ stimulus train that overcame inhibition. $A$, Simultaneous responses before the stimulus train. Note single first spikes and suppression of the second spike (arrows) in response to $2 \mathrm{~Hz}$ stimulation. $B$, During the first seconds of the $10 \mathrm{sec} 20 \mathrm{~Hz}$ train, perforant path stimuli evoke large amplitude population spikes and recurrent inhibition remains intact (alternating spike suppression; arrows). $C$, Toward the end of the stimulus train, inhibition is overcome and all stimuli evoke large amplitude population spikes. $D$, Immediately after the end of the stimulus train, $2 \mathrm{~Hz}$ stimuli evoke multiple discharges at one site and small field changes at the other site. Note that the spikes recorded at one site are not detected by the other electrode. $E$, Within seconds after the recording in $D, 2 \mathrm{~Hz}$ stimuli evoke distinct, highly synchronous, large-amplitude granule cell population spikes from normally independent segments. Note that each recording electrode records distinct events. This is evident from the traces, which show that some spikes (arrows) are recorded at one site but are barely detected by the other electrode, located only $1.0 \mathrm{~mm}$ away. Calibration: $5 \mathrm{mV}$ and $10 \mathrm{msec}$ in $A-C, 5 \mathrm{mV}$ and $20 \mathrm{msec}$ in $D$ and $E$.

activate inhibitory granule cells that produce lateral inhibition in nontargeted mitral cells (DeVries and Baylor, 1993). Thus, feedforward and feedback lateral inhibitory mechanisms create an inhibitory field penetrable only by strong excitatory stimuli, thereby directing excitation to specifically targeted neurons.
The bicuculline-induced lateral inhibition we have demonstrated in the normal dentate gyrus is reminiscent of the "inhibitory surround" described by Prince and Wilder (1967) around a neocortical penicillin focus, or the "ring" of inhibition reported by Dichter and Spencer (1969) around a penicillin focus 


\section{A Intravenous bicuculline}

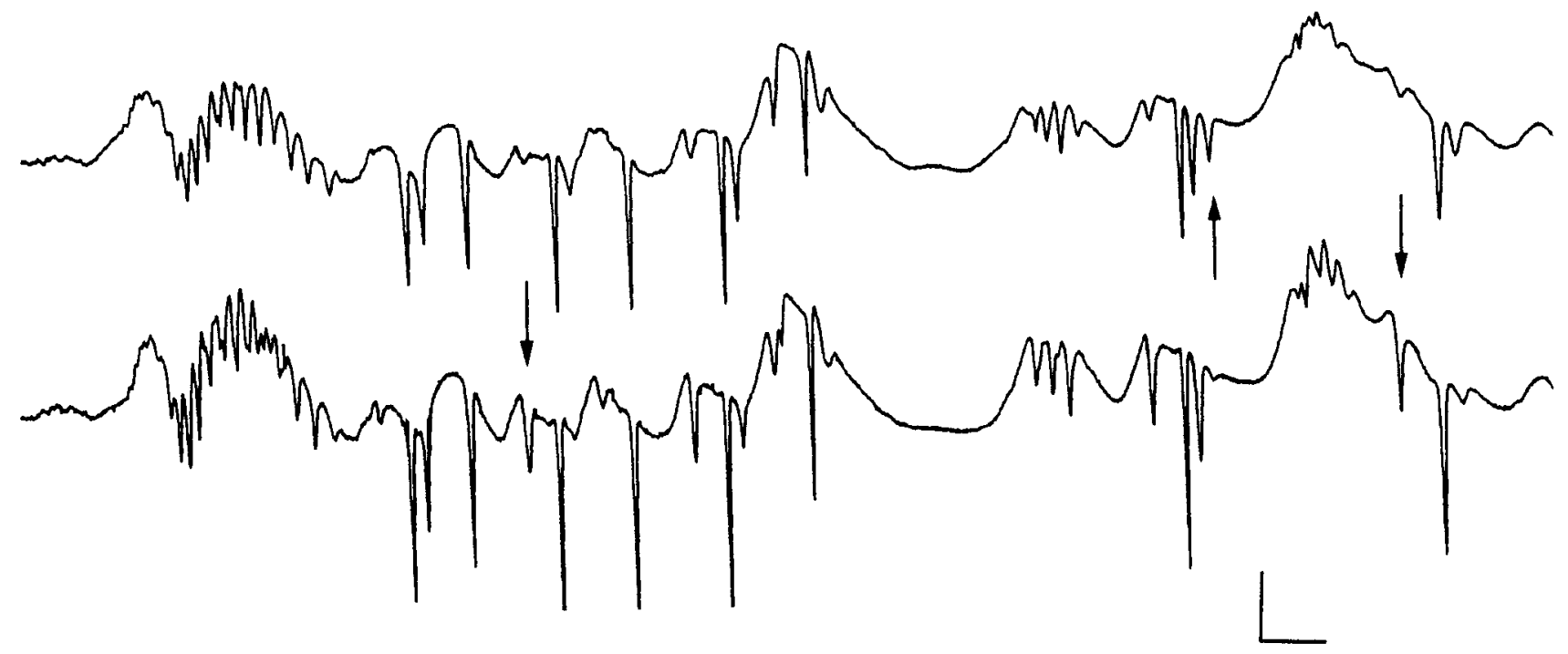

B Intrahippocampal bicuculline methiodide

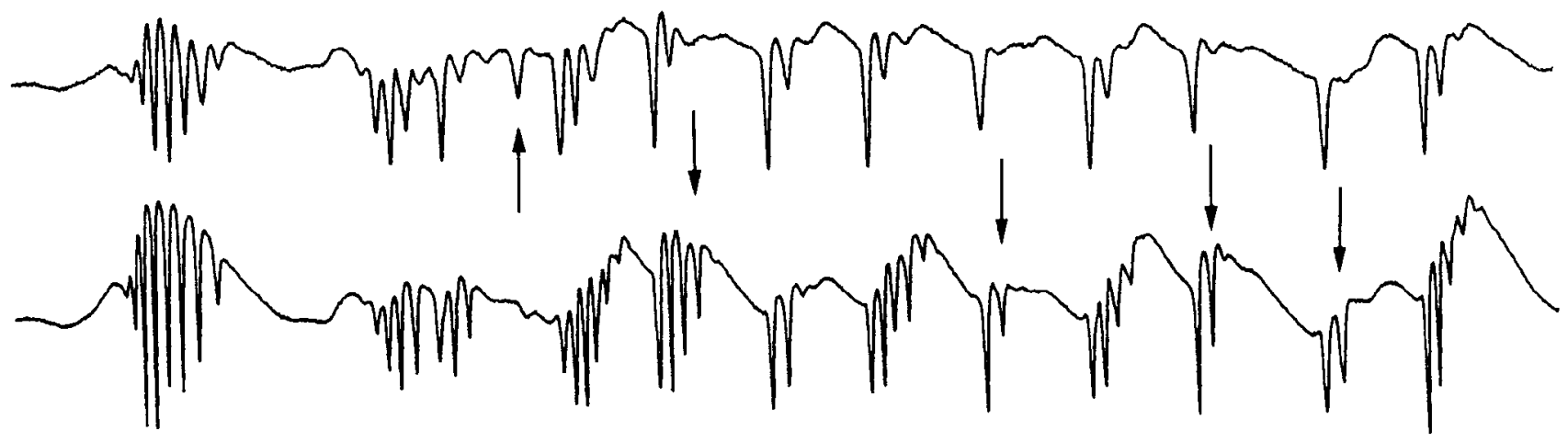

Figure 7. Spontaneous granule cell population discharges after intravenous or intrahippocampal bicuculline. Spontaneous activity within the granule cell layer was recorded simultaneously at two sites $1.0 \mathrm{~mm}$ apart along the longitudinal axis. After either $(A)$ intravenous injection $(0.75$ $\mathrm{mg}$ bicuculline base $/ \mathrm{kg}$ ) or $(B)$ intrahippocampal injection through the Hamilton syringe/electrode ( $0.5 \mu \mathrm{l} 25$ mm bicuculline methiodide), normally independent segments of the granule cell layer exhibited highly synchronous spontaneous granule cell discharges. Note that although the discharges in both segments were highly synchronous, they were not identical in that some spikes (arrows) were recorded by one electrode but not the other. Calibration, $5 \mathrm{mV}$ and $20 \mathrm{msec}$.

on the surface of the hippocampus. Both groups envisaged this inhibition as preventing the spread of epileptiform discharges from the site of seizure origination. However, the present studies are distinct from these earlier studies in that no "focus" of spontaneous epileptiform discharges was produced. Leakage of bicuculline from a microelectrode tip produced no detectable spontaneous activity; the only apparent change was a highly localized disinhibition that produced multiple discharges only in response to afferent stimulation. Thus, the use of the bicuculline electrode method revealed lateral or surround inhibition resulting from brief, highly localized, evoked discharges, and not in response to spontaneous epileptiform discharges.

Given the existence of powerful and remarkably long-lasting lateral inhibition in the granule cell layer, and the shorter latency and greater sensitivity of dentate nongranule cells than granule cells to excitation by perforant path fibers (Buzsáki and Eidelberg, 1982; Scharfman, 1991), we proposc that normal cxcitatory neocortical stimuli intended for a specifically targeted la- mella may first excite nonprincipal cells, enabling them to increase feedforward inhibition in preparation for the imminent excitation of the granule cells. In this way, intralamellar and translamellar inhibition could, in advance of granule cell excitation, create an inhibitory field penetrable only by strong excitatory inputs. By activating inhibition in surrounding segments of the granule cell layer just before the targeted granule cells are excited, incoming stimuli from entorhinal projections could focus excitation to the specifically targeted principal cells. Thus, functional separation and lateral inhibition may establish a large number of independent functional subunits, which, when activated in unique combinations, permit a large number of possible functional responses, each corresponding to unique cortical events. Lamellar function may, therefore, permit complex information processing in what appears superficially to be a relatively simple longitudinal structure, as originally envisaged by Andersen and colleagues (1971).

Although the functional implications of longitudinally di- 
rectcd latcral inhibition are of obvious significance to the lamellar hypothesis of hippocampal function (Andersen et al., 1971; Amaral and Witter, 1989; Lothman et al., 1991), the possible functional significance of lateral inhibition in the transverse or radial axes is less clear. Anatomical studies show that entorhinal cortical neurons innervate the entire transverse extent of the granule cell layer (Tamamaki and Nojyo, 1993). Therefore, although bicuculline restricted to one locus of the granule cell layer produced lateral inhibition in all directions, normal neocortical cxcitation may overcome transverse inhibition and excite an entire transverse lamella in order to convey the appropriate message to the corresponding "slice" of CA3 pyramidal cells. Thus, the structural network organization of the dentate gyrus, that is, rough topographic specificity of entorhinal projections to corresponding septotemporal segments of the granule cell layer (Witter et al., 1989), elliptical granule cell dendritic trees, which are $2-4$ times broader in the transverse than the longitudinal plane (Desmond and Levy, 1982; Claiborne et al., 1990), innervation of the cntire transversc dentatc "slice" by perforant path fibers (Tamamaki and Nojyo, 1993), and longitudinal projections of hilar neurons that may evoke lateral inhibition (Amaral and Witter, 1989), may place a longitudinal constraint on "surround" inhibition. That is, longitudinal lateral inhibition and lamellar function may be the primary functional design in the dentate gyrus.

However, the possibility that surround inhibition may define functional separation in several directions must be considered. It is possible that different afferents to the dentate hilar region from the septum (Frotscher and Leranth, 1986; Freund and Antal, 1988), locus coeruleus (Koda et al., 1978), and raphe nuclei (Moore and Halaris, 1975), for examples, differentially regulate specific inhibitory neuron and mossy cell subpopulations, and influence different groups of granule cells. Thus, given the heterogeneity of dentate inhibitory neurons and their axonal projections (Halasy and Somogyi, 1993), it is theoretically possible that granule cells are functionally separated in both the transverse and longitudinal directions.

Because the dentate hilar "mossy" cells (Amaral, 1978) are glutamate immunoreactive (Soriano and Frotscher, 1994), and preferentially innervate segments of the granule cell layer that are distant from their somata (Amaral and Witter, 1989), they may be the cell type primarily responsible for establishing longitudinal lateral inhibition in the granule cell layer (Sloviter, 1994). However, it remains to be determined if, and how effectively, mossy cells excite inhibitory neurons and granule cells. Lateral or surround inhibition may also be the result of transverse and longitudinal projections of inhibitory cells (Struble et al., 1978; Buckmaster and Schwartzkroin, 1993). Clearly, although we have demonstrated lateral inhibition in the dentate gyrus, our data do not identify the cells that mediate it.

\section{Relevance to temporal lobe epilepsy}

In addition to their implication for normal hippocampal function, the results of these experiments may be relevant to the pathogenesis of temporal lobe epilepsy. In the only detailed postmortem analysis of the entire brains of patients with chronic temporal lobe epilepsy, Margerison and Corsellis (1966) described a specific pattern of brain damage including changes in the hippocampus, amygdala, thalamus, and cerebellum. Significantly, hippocampal damage was the most consistent finding in patients with any temporal lobe pathology. In no case did extrahippocampal damage exist in the temporal lobe without hippocampal damage also being present. Within the hippocampus, extensive loss of dentate hilar neurons was not only a consistent finding but was, in some cases, the only pathology in the temporal lobe (Margerison and Corsellis, 1966). Because many patients with hippocampal sclerosis experience status epilepticus, prolonged febrile seizures, or head trauma before epilepsy develops (Bruton, 1988, Cendes et al., 1993; French et al., 1993), and because prolonged seizures or head injury produce similar selective dentate hilar cell loss and granule cell hyperexcitability in experimental animals (Sloviter, $1991 \mathrm{~b}$; Lowenstein ct al., 1992), hilar neuron loss has been suggested to be the common pathological denominator and primary network defect underlying development of hippocampal-onset seizures in some cases (Sloviter, 1994). If vulnerable hilar neurons mediate lateral inhibition in the normal granule cell layer, their loss would be predicted to decrease translamellar granule cell inhibition. Therefore, our hypothesis predicts that once lateral inhibition is decreased as a result of the loss of the cells that mediate it, normally independent segments of the granule cell layer would coalesce functionally to form an "epileptic aggregate" capable of responding to afferent stimuli with multilamellar discharges (Sloviter, 1994).

The present results are consistent with this hypothesis insofar as they demonstrate lateral inhibition as an operant mechanism in the normal dentate gyrus and show that granule cells in normally independent segments of the granule cell layer have an inherent tendency to discharge in synchrony when disinhibited. This latter obscrvation is surprising becausc, unlike CA3 pyramidal cells (Miles and Wong, 1986), granule cells lack recurrent excitatory connections. It is, therefore, necessary to explain how synaptically unconnected granule cells could have an underlying propensity for population discharges. Recent studies by Dudek and colleagues suggest that granule cell epileptiform behavior may result from ephaptic interactions, that is, nonsynaptic field effects that depolarize disinhibited granule cells (Dudek et al., 1986; Snow and Dudek, 1986; Schweitzer et al., 1992). These authors concluded that increased extracellular potassium and decreased calcium are sufficient to induce synchronous granule cell population discharges within a hippocampal slice. The fact that the development of these synchronous granule cell discharges was found to be independent of synaptic activity reinforced the possibly ephaptic nature of the behavior (Schweitzer et al., 1992). If correct, this explanation, taken together with the present results, implies that dentate granule cells, like other cell populations (McBain et al., 1990), are sensitive to excitation-induced changes in the extracellular ionic environment and may be capable of behaving as a "functional syncytium" when GABA-mediated inhibition is decreased.

\section{References}

Amaral DG (1978) A Golgi study of cell types in the hilar region of the hippocampus in the rat. J Comp Neurol 182:851-914.

Amaral DG, Witter MP (1989) The three dimensional organization of the hippocampal formation: a review of anatomical data. Neuroscience 31:571-591.

Andersen P, Lomo T (1967) Control of hippocampal output by afferent volley frequency. Prog Brain Res 27:400-412.

Andersen P, Holmqvist B, Voorhoeve PE (1966) Entorhinal activation of dentate granule cells. Acta Physiol Scand 66:448-460.

Andersen P, Bliss TVP, Skrede KK (1971) Lamellar organization of hippocampal excitatory pathways. Exp Brain Res 13:222-238.

Ben-Ari Y, Krnjevic K, Reinhardt W (1979) Hippocampal seizures and failure of inhibition. Can J Physiol 57:1462-1466.

Blackstad TW, Brink K, Hem J, Jeune B (1970) Distribution of hip- 
pocampal mossy fibers in the rat. An experimental study with silver impregnation methods. J Comp Neurol 138:433-450.

Bruton CJ (1988) The neuropathology of temporal lobe epilepsy. New York: Oxford UP

Buckmaster PS, Schwartzkroin PA (1993) Interneurons and inhibition in the dentate gyrus of the rat in vivo. Soc Neurosci Abstr 19:351.

Buzsáki G, Eidelberg E (1982) Direct afferent excitation and long-term potentiation of hippocampal interneurons. J Neurophysiol 48:597607.

Cendes F, Andermann F, Gloor P, Lopes-Cendes I, Andermann E, Melanson D, Jones-Gotman M, Robitaille Y, Evans A, Peters T (1993) Atrophy of mesial structures in patients with temporal lobe epilepsy: cause or consequence of repeated seizures? Ann Neurol 34: 795-801.

Claiborne BJ, Amaral DG, Cowan WM (1990) Quantitative, threedimensional analysis of granule cell dendrites in the rat dentate gyrus. J Comp Neurol 302:206-219.

deLanerolle NC, Kim JH, Robbins RJ, Spencer DD (1989) Hippocampal interneuron loss and plasticity in human temporal lobe epilepsy. Brain Res 495:387-395.

Desmond NL, Levy WB (1982) A quantitative anatomical study of the granule cell dendritic fields of the rat dentate gyrus using a novel probabilistic method. J Comp Neurol 212:131-145.

DeVries SH, Baylor DA (1993) Synaptic circuitry of the retina and olfactory bulb. Neuron [Rev Suppl] 10:139-149.

Dichter M, Spencer WA (1969) Penicillin-induced interictal discharges from the cat hippocampus. II. Mechanisms underlying origin and restriction. J Neurophysiol 32:663-687.

Dudek FE, Snow RW, Taylor CP (1986) Role of electrical interactions in synchronization of epileptiform bursts. In: Advances in neurology (Delgado-Escueta AV, Ward AA Jr, Woodbury DM, eds), pp 593617. New York: Raven.

Eccles JC (1973) The understanding of the brain. New York: McGrawHill.

French JA, Williamson PD, Thadani VM, Darcey TM, Mattson RH, Spencer SS, Spencer DD (1993) Characteristics of medial temporal lobe epilepsy: I. Results of history and physical examination. Ann Neurol 34:774-780.

Freund T, Antal M (1988) GABA-containing neurons in the septum control inhibitory interneurons in the hippocampus. Nature 336:170173.

Frotscher M, Leranth C (1986) The cholinergic innervation of the rat fascia dentata: identification of target structures on granule cells by combining choline acetyltransferase immunocytochemistry and Golgi impregnation. J Comp Neurol 243:58-70.

Gaarskjaer FB (1986) The organization and development of the hippocampal mossy fiber system. Brain Res 396:335-357.

Halasy K, Somogyi P (1993) Subdivisions in the multiple GABAergic innervation of granule cells in the dentate gyrus of the rat hippocampus. Eur J Neurosci 5:411-429.

Koda LY, Wise RA, Bloom FE (1978) Light and electron microscopic changes in the rat dentate gyrus after lesions or stimulation of the ascending locus coeruleus pathway. Brain Res 144:363-368.

Lorente de Nó R (1934) Studies on the structure of the cerebral cortex. II. Continuation of the study of the ammonic system. J Psychol Neurol (Lpz) 46:113-177.

Lothman EW, Bertram EH, Stringer JL (1991) Functional anatomy of hippocampal seizures. Prog Neurobiol 37:1-82.

Lowenstein DH, Thomas MJ, Smith DH, McIntosh TK (1992) Selective vulnerability of dentate hilar neurons following traumatic brain injury: a potential mechanistic link between head trauma and disorders of the hippocampus. J Neurosci 12:4846-4853.

Margerison JH, Corsellis JAN (1966) Epilepsy and the temporal lobes: a clinical encephalographic and neuropathological study of the brain in epilepsy, with particular reterence to the temporal lobes. Brain 89 499-530.

McBain CJ, Traynelis SF, Dingledine R (1990) Regional variation of extracellular space in hippocampus under physiological and pathological conditions. Science 249:674-677.

Meldrum BS, Bruton CJ (1992) Epilepsy. In: Greenfield's neuropathology (Adams JH, Duchen LW, eds), pp 1246-1283. New York: Oxford UP

Miles R, Wong RKS (1986) Excitatory synaptic intcractions between CA3 neurons in the guinea pig hippocampus. J Physiol (Lond) 373 : $397-418$.

Moore RY, Halaris AE (1975) Hippocampal innervation by serotonin neurons of the midbrain raphe in the rat. J Comp Neurol 164:171184.

Prince DA, Wilder BJ (1967) Control mechanisms in cortical epileptogenic foci; "surround" inhibition. Arch Neurol 16:194-202.

Ramón y Cajal S (1893) Estructura del asta de Ammon. Anat Soc Esp Histol Nat Madrid 22:53-114.

Ramón y Cajal S (1968) The structure of Ammon's horn. Springfield: Thomas.

Scharfman HE (1991) Dentate hilar cells with dendrites in the molecular layer have lower thresholds for synaptic activation by perforant path than granule cells. J Neurosci 11:1660-1673.

Schweitzer JS, Patrylo PR, Dudek FE (1992) Prolonged field bursts in the dentate gyrus: dependence on low calcium, high potassium, and nonsynaptic mechanisms. J Neurophysiol 68:2016-2025.

Sloviter RS (1983) "Epileptic" brain damage in rats induced by sustained electrical stimulation of the perforant path. I. Acute electrophysiological and light microscopic studies. Brain Res Bull 10:675697.

Sloviter RS (1987) Decreased hippocampal inhibition and a selective loss of interneurons in experimental epilepsy. Science 235:73-76.

Sloviter RS (1991a) Feedforward and feedback inhibition of hippocampal principal cell activity evoked by perforant path stimulation; GABA-mediated mechanisms that regulate excitability in vivo. Hippocampus 1:31-40.

Sloviter RS (1991b) Permanently altered hippocampal structure, excitability and inhibition after experimental status epilepticus in the rat; the "dormant basket cell" hypothesis and its possible relevance to temporal lobe epilepsy. Hippocampus 1:41-66.

Sloviter RS (1994) The functional organization of the hippocampal dentate gyrus and its relevance to the pathogenesis of temporal lobe epilepsy. Ann Neurol 35:640-654.

Snow RW, Dudek FE (1986) Evidence for neuronal interactions by electrical field effects in the CA3 and dentate regions of rat hippocampal slices. Brain Res 367:292-295.

Soriano E, Frotscher M (1994) Mossy cells of the rat fascia dentata are glutamate-immunoreactive. Hippocampus 4:65-70.

Steward O, Tomasulo R, Levy WB (1990) Blockade of inhibition in a pathway with dual excitatory and inhibitory action unmasks a capability for LTP that is otherwise not expressed. Brain Res 516:292300.

Struble RG, Desmond NL, Levy WB (1978) Anatomical evidence for interlamellar inhibition in the fascia dentata. Brain Res 152:580-585.

Tamamaki N, Nojyo Y (1993) Projection of the entorhinal layer II neurons in the rat as revealed by intracellular pressure-injection of neurobiotin. Hippocampus 3:471-480.

Thompson SM, Gahwiler BH (1989) Activity-dependent disinhibition. I. Repetitive stimulation reduces IPSP driving force and conductance in the hippocampus in vitro. J Neurophysiol 61:501-511.

Witter MP, Groenewegen HJ, Lopes da Silva FH, Lohman AHM (1989) Functional organization of the extrinsic and intrinsic circuitry of the parahippocampal region. Prog Neurobiol 33:1610-254. 